\title{
Susceptibility of rodent cell lines to rat coronaviruses and differential enhancement by trypsin or DEAE-dextran
}

\author{
Diane J. Gaertner, Abigail L. Smith, F. X. Paturzo, and R. O. Jacoby \\ Section of Comparative Medicine, Yale University School of Medicine, New Haven, \\ Connecticut, U.S.A.
}

Accepted October 21, 1990

\begin{abstract}
Summary. Cell lines of rodent origin were tested for susceptibility to infection with rat coronavirus (RCV), including sialodacryoadenitis virus (SDAV) and Parker's rat coronavirus (PRCV). LBC rat mammary adenocarcinoma cells were susceptible only if the cells were treated with diethylaminoethyl-dextran (DEAE-D). A recent report that RCVs grow well in L2 mouse fibroblast cells was confirmed and expanded. RCV infection of L2 cells was substantially enhanced by treatment of cells with trypsin but not by treatment with DEAED. Primary isolation of SDAV from experimentally infected rats was accomplished using trypsin-treated L2 cells. One of 13 additional cell lines tested (rat urinary bladder epithelium, RBL-02) supported growth of RCVs, and growth was slightly enhanced by DEAE-D, but not by trypsin. These refinements of in vitro growth conditions for RCVs should facilitate further studies of their basic biology and improve options for primary isolation.
\end{abstract}

\section{Introduction}

Rat coronaviruses (RCVs), notably sialodacryoadenitis virus (SDAV) and Parker's rat coronavirus (PRCV), infect laboratory rats at high prevalence, cause clinically and economically significant disease and interfere with research using rats [7]. Diagnostic and experimental studies of RCVs have been limited by the lack of a reliable cell line in which to grow the viruses [7]. RCVs have traditionally been grown in primary rat kidney (PRK) cells or infant mouse brain but these techniques require the use of animals and are labor intensive. Although many coronaviruses have fastidious growth requirements, replicating only in organ cultures or cell lines derived from the animal or tissue of origin, cell lines supporting growth of most coronaviruses have been identified $[5,7]$. Attempts to grow SDAV in a variety of rodent cell lines, including mouse neuroblastoma (clone N18) cells, C6 rat glial cells, and MHV-susceptible cell lines such as NCTC 1469 cells failed (L. E. Garlinghouse and A. L. Smith, 
unpubl. data). Recently Hirano et al. reported that a rat mammary adenocarcinoma cell line (LBC) supported RCV growth [4], and Percy et al. reported that L2 cells supported RCVs [11]. In studies reported here, LBC cells, L2 cells and 13 other cell lines of rodent origin were tested for their susceptibility to RCVs. A rat bladder epithelial cell line (RBL-02) was identified which supports RCV growth. Medium containing trypsin or diethylaminoethyl-dextran (DEAE-D), which have been used to enhance the growth of other coronaviruses $[17,19]$, also differentially enhanced RCV growth in selected cell lines.

\section{Materials and methods}

\section{Cells and media}

The cell lines tested and media used are listed in Table 1. HH cells were obtained by in vitro transformation of PRK cells [9] by high multiplicity infection with SV-40 [20]. Cell cultures were grown in $25 \mathrm{~cm}^{2}$ polystyrene flasks (Corning Glassworks, Corning, NY) at $37^{\circ} \mathrm{C}$ in a humidified $5 \% \mathrm{CO}_{2}$ atmosphere and were maintained in media containing $100 \mu \mathrm{g} /$ $\mathrm{ml}$ streptomycin and 100 units $/ \mathrm{ml}$ penicillin. All media and supplements were purchased from GIBCO BRL (Gaithersburg, MD), except MCDB-151 and F-12 media (Sigma Chemical Co., St. Louis, MO). Cells were transferred when confluent using $0.12 \%$ trypsin and $0.27 \mathrm{mM}$ EDTA. Two sublines of L2 cells obtained from different laboratories were used (Table 1). Cell lines received from extramural sources except the American Type Culture Collection were tested for Mycoplasma spp. and were culture-negative.

\section{Virus}

Stocks of SDAV, strain 681 (SDAV-681), and Parker's rat coronavirus (PRCV) were prepared in infant mouse brain [2,3]. Titration of PRCV and SDAV-681 stocks in primary rat kidney cells $[2,3]$ yielded titers of $10^{7} \mathrm{TCID}_{50}$ and $10^{6.5} \mathrm{TCID}_{50}$ per $\mathrm{ml}$, respectively. The SDAV stock used for concurrent L2 and mouse titration was one infant mouse passage removed from the stock used for cell culture inoculations.

\section{Animals}

Cr: ORL Sencar dams with litters were purchased (Animal Genetics and Production Branch, National Institutes of Health, Bethesda, MD) and housed under conditions which met or exceeded standards of the U.S. Public Health Service.

\section{Virus infection}

When cell monolayers were approximately $80 \%$ confluent, growth medium (Table 1) was removed and cultures were exposed to $1.0 \mathrm{ml}$ of a $1 \%$ suspension of virus-infected mouse brain or $1.0 \mathrm{ml}$ of diluent. Fetal calf serum (FCS) was omitted from medium used for trypsin- or DEAE-D-treated cells. Following virus absorption at $37^{\circ} \mathrm{C}$ for $1 \mathrm{~h}, 4 \mathrm{ml}$ of medium were added to all flasks. Cultures were observed daily. Cytopathic effect (CPE) was typified by syncytium formation. The percentage of the monolayer that consisted of syncytia was estimated, and all infected and mock-inoculated cultures were harvested at $72 \mathrm{~h}$ post-inoculation.

\section{Fluorescence microscopy}

Cells no longer adherent to the plastic and cells scraped from the flask surface were washed separately twice, air-dried on Teflon-coated slides (Cel-line Associated, Newfield, NJ) and fixed in ice cold acetone for at least $15 \mathrm{~min}$. 


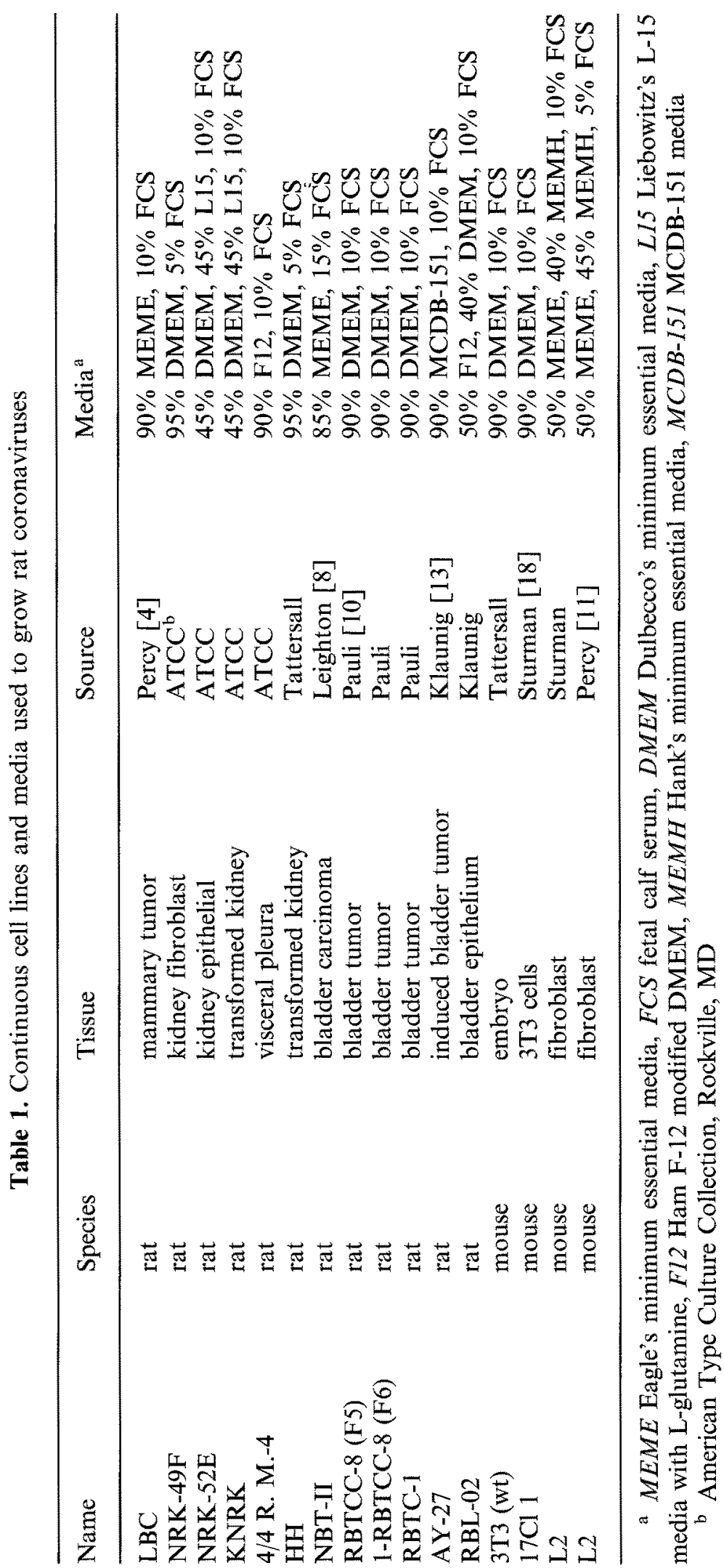


Air-dried, fixed cells were incubated with SDAV-immune mouse ascitic fluid or with pooled SDAV-immune serum from experimentally infected rats followed by incubation with fluoresceinated goat anti-species immunoglobulin (Antibodies, Inc., Davis, CA) containing $0.01 \%$ Evans's blue [14]. Cells were examined at a magnification of $\times 200$ with a transmitted light fluorescence microscope.

\section{Treatment with trypsin or DEAE-D}

Concentrations of porcine parvovirus-free, Mycoplasma-free trypsin (GIBCO BRL) from $0.016 \mu \mathrm{g} / \mathrm{ml}$ to $40 \mu \mathrm{g} / \mathrm{ml}$ were added to the absorption and incubation media for L2 (Percy) and RBL-02 cells. Since some tissue homogenates in combination with $16 \mu \mathrm{g} / \mathrm{ml}$ trypsin were toxic to $\mathrm{L} 2$ (Percy) cells, $1.6 \mu \mathrm{g} / \mathrm{ml}$ of trypsin was used. Trypsin-treated uninoculated cells were included at each concentration to control for toxicity. Four ml of trypsincontaining medium were added for incubation.

Concentrations of $0,50,100,200$ and $400 \mu \mathrm{g} / \mathrm{ml}$ of DEAE-D (Pharmacia Fine Chemicals, Uppsala, Sweden) were added to the pre-absorption and absorption media of $L B C$, L2 (Percy) and RBL-02 cells to allow sufficient time for action on cell membranes. Duplicate cultures were pre-treated with DEAE-D-containing medium for $4 \mathrm{~h}$, and virus or diluent was added for $1 \mathrm{~h}$ at $37^{\circ} \mathrm{C}$ [19]. DEAE-D containing medium was replaced with growth medium for incubation.

\section{Virus isolation from rat tissues}

Nasal washes, lungs and salivary and lacrimal glands from control rats or rats experimentally infected with SDAV-681 were provided by Dr. Eleanor C. Weir, Yale University. The tissues had previously been tested for the presence of infectious virus by intracerebral inoculation of infant mice [21] and had been stored at $-70^{\circ} \mathrm{C}$ until use in this study. One $\mathrm{ml}$ of a $3-5 \%(\mathrm{w} / \mathrm{v})$ tissue homogenate in trypsin-containing medium $(1.6 \mu \mathrm{g} / \mathrm{ml})$ was used for inoculation of L2 (Percy) cells. Because lacrimal and salivary gland inocula were toxic to L2 (Percy) cells, they were removed following absorption. Nasal wash and lung inocula were not removed. Cells were examined daily for CPE by an observer uninformed of their status in the prior mouse inoculation study. Cells were subsequently processed and stained for viral antigen.

\section{Concurrent titration of SDAV-681 in infant mice and $L 2$ cells}

Serial ten-fold dilutions of stock SDAV-681 virus were inoculated intracerebrally into 2day old Sencar mice and into flasks containing L2 (Percy) cells in trypsin $(1.6 \mu \mathrm{g} / \mathrm{ml})$ supplemented medium. Mouse mortality at each dilution was recorded for 14 days. L2 (Percy) cells were observed daily for CPE and were stained for viral antigen $72 \mathrm{~h}$ after inoculation. Titers expressed as $\mathrm{LD}_{50}$ or $\mathrm{TCID}_{50}$ per $\mathrm{ml}$ were calculated [12].

\section{Results \\ Growth of RCVs in cell lines \\ L2 (Percy) cells}

Antigen-positive cells by immunofluorescence (IF) staining $(<5 \%)$ were observed on most attempts in the first passage of SDAV in L2 (Percy) cells. In the second passage, syncytium formation involving about $5 \%$ of the monolayer was observed and about $10 \%$ of cells were antigen-positive. The proportion of antigen-positive cells increased to about $20 \%$ in the third passage. The suscep- 


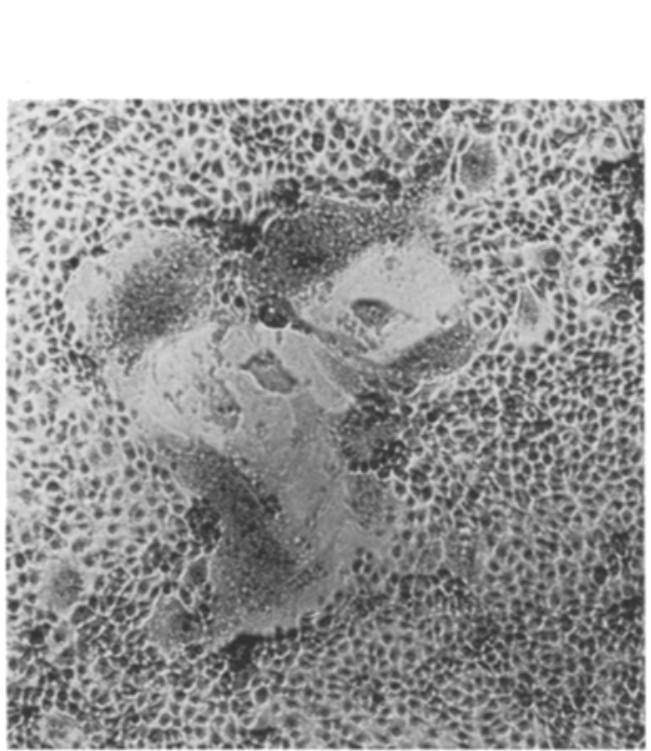

Fig. 1

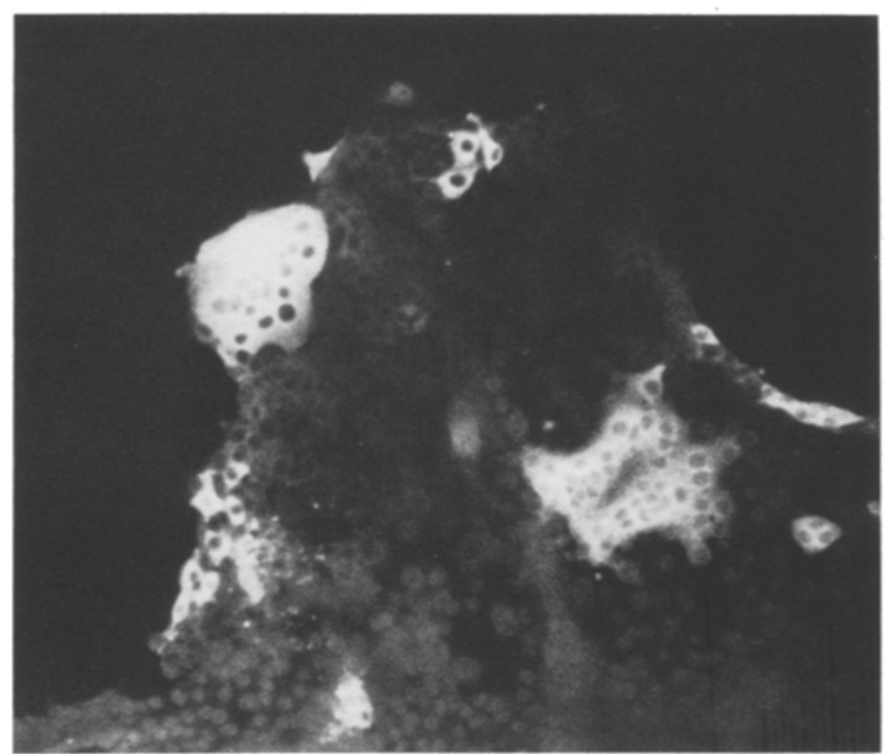

Fig. 2

Fig. 1. Cytopathic effect (syncytium) in unstained RBL-02 cells $48 \mathrm{~h}$ post-inoculation with sialodacryoadenitis virus, strain $681(\times 350)$

Fig. 2. Multiple fluorescent syncytia formed by sialodacryoadenitis virus, strain 681 in RBL02 cells at $72 \mathrm{~h}$ post-inoculation $(\times 875)$

tibility of L2 (Percy) cells to PRCV was erratic. Less than 5\% of the monolayer formed syncytia, and antigen-positive cells $(<5 \%)$ were seen on the first passage in half of the attempts, whereas PRCV growth was not detected in the remaining attempts. Seven additional passages did not enhance PRCV growth.

\section{RBL-02 cells}

SDAV-681 and PRCV grew in the first passage in RBL-02 cells. Syncytia involving $5 \%$ of the monolayer formed within $48 \mathrm{~h}$ (Fig. 1) and antigen-positive cells (about $5 \%$ ) were seen by IF staining (Fig. 2). CPE was not seen in the second passage, and fewer cells contained antigen. Virus growth was not detected in the third through seventh passages.

\section{LBC cells}

Repeated attempts, including 11 blind passages, failed to reveal growth of SDAV-681 or PRCV in LBC cells. CPE was not seen, and virus antigen was not detected.

\section{Other cell lines}

RCV growth was not detected in other cell lines listed in Table 1. At least 2 passage attempts of both SDAV-681 and PRCV were completed in all cell lines. 
Table 2. Effect of trypsin on growth of rat coronaviruses in L2 and RBL-02 cells

\begin{tabular}{|c|c|c|c|c|c|c|}
\hline \multirow[t]{3}{*}{ Cell line } & \multirow[t]{3}{*}{ Treatment } & \multirow[t]{3}{*}{ Passage no. } & \multicolumn{4}{|c|}{ Virus strain } \\
\hline & & & \multicolumn{2}{|c|}{ SDAV } & \multicolumn{2}{|c|}{ PRCV } \\
\hline & & & $C P E^{a}$ & antigen $^{\mathrm{b}}$ & CPE & antigen \\
\hline \multirow{5}{*}{ L2 (Percy) } & none & 1 & - & $+^{c}$ & + & $+^{d}$ \\
\hline & & 2 & + & + & - & - \\
\hline & & 3 & + & + & - & - \\
\hline & trypsin ${ }^{\mathrm{e}}$ & 1 & + & + & + & + \\
\hline & & 2 & - & - & - & - \\
\hline \multirow[t]{5}{*}{ RBL-02 } & none & 1 & + & + & + & + \\
\hline & & 2 & - & + & - & - \\
\hline & & 3 & - & - & - & - \\
\hline & trypsin ${ }^{\mathrm{f}}$ & 1 & - & - & - & + \\
\hline & & 2 & - & - & - & - \\
\hline
\end{tabular}

a Syncytia formation

b As detected by indirect immunofluorescence of non-adherent or adherent cells

c One fifth of attempts unsuccessful

${ }^{d}$ One half of attempts unsuccessful

e $1.6 \mu \mathrm{g} / \mathrm{ml}$

${ }^{\mathrm{f}} 0.16 \mu \mathrm{g} / \mathrm{ml}$, higher concentrations of trypsin were toxic to RBL-02 cells

\section{Enhancement of $R C V$ growth by trypsin}

Trypsin enhanced growth of RCVs in L2 (Percy) cells in the first passage (Table 2), but not in LBC (data not shown) or RBL-02 cells. After treatment with trypsin, about $10 \%$ of inoculated L2 (Percy) cells developed medium-sized syncytia, whereas syncytia were not seen in untreated SDAV-681-inoculated L2 (Percy) cells. Trypsin treatment also increased the proportion of antigenpositive L2 (Percy) cells to about $10 \%$. Increased trypsin concentration up to $16 \mu \mathrm{g} / \mathrm{ml}$ increased the proportion of infected L2 (Percy) cells, but concentrations higher than $16 \mu \mathrm{g} / \mathrm{ml}$ were toxic. RBL-02 cells were treated with a 10 -fold lower concentration of trypsin than L2 (Percy) cells due to a lower toxicity threshold.

\section{Enhancement of $R C V$ growth by DEAE-dextran}

Concentrations of $50-400 \mu \mathrm{g} / \mathrm{ml}$ of DEAE-D substantially enhanced growth of RCVs in LBC cells, enhanced growth marginally in RBL-02 cells, and did not affect growth in L2 (Percy) cells (Table 3). Viral antigen was not detected in mock-treated, inoculated LBC cells, but about $10 \%$ of non-adherent cells were virus antigen-positive in treated, inoculated cultures following exposure to 
Table 3. Effect of DEAE-dextran on growth of rat coronaviruses in L2, RBL-02 and LBC cells $^{\mathrm{a}}$

\begin{tabular}{lllllll}
\hline Cell & Virus & \multicolumn{7}{l}{ DEAE-dextran $(\mu \mathrm{g} / \mathrm{ml})$} & \\
\cline { 2 - 6 } & & 0 & 50 & 100 & 200 & 400 \\
\hline L2 (Percy) & SDAV & \pm & \pm & \pm & - & - \\
\multirow{2}{*}{ RBL-02 } & PRCV & - & \pm & - & - & - \\
& SDAV & \pm & \pm & \pm & + & \pm \\
LBC & PRCV & - & \pm & + & + & + \\
& SDAV & - & + & + & + & + \\
& PRCV & - & \pm & + & + & + \\
\hline
\end{tabular}

${ }^{a}$ As detected by viral antigen in adherent or non-adherent cells, - not detected, \pm less than $5 \%$ cells positive, $+>5 \%$ cells positive

$200-400 \mu \mathrm{g} / \mathrm{ml}$ of DEAE-D. Enhancement of RCV growth in DEAE-D-treated RBL-02 cells was marginal and evident only by examination of non-adherent cells stained for virus antigen.

\section{Use of trypsin-treated L2 (Percy) cells for primary isolation and quantification of $S D A V-681$}

In a single attempt to isolate SDAV-681 from the lung of an experimentally infected rat, syncytia and viral antigen were first seen after 6 passages in untreated L2 (Percy) cells. In contrast, syncytia and antigen were observed in the first passage in trypsin-treated L2 (Percy) cells. Based on this finding, a small study was initiated to ascertain the sensitivity of trypsin-treated L2 (Percy) cells for primary isolation of RCVs.

Table 4. Comparison of trypsin-treated L2 (Percy) cells and mouse inoculation for isolation of SDAV from experimentally infected rats

\begin{tabular}{lcccc}
\hline \multirow{2}{*}{ Tissue } & \multicolumn{2}{c}{ L2 cells } & Mouse inoculation \\
\cline { 2 - 4 } & $\mathrm{CPE}^{\mathrm{a}}$ & $\mathrm{IF}^{\mathrm{b}}$ & combined & \\
\hline Lung & $10 / 15^{\mathrm{c}}$ & $10 / 15$ & $12 / 15$ & $15 / 15$ \\
Lacrimal gland & $2 / 7$ & $2 / 7$ & $2 / 7$ & $6 / 7$ \\
Salivary gland & $2 / 7$ & $5 / 7$ & $5 / 7$ & $6 / 7$ \\
Nasal wash & $6 / 9$ & $7 / 9$ & $7 / 9$ & $8 / 9$ \\
\hline
\end{tabular}

\footnotetext{
a Syncytia formation

b Indirect immunofluorescence

c Number positive/number examined
} 
Virus isolations were attempted using tissue homogenates previously tested for SDAV-681 by infant mouse inoculation (Table 4). CPE and virus antigen were observed in $57 \%$ and $69 \%$, respectively, of cultures exposed to viruspositive tissues. The highest concordance between mouse and L2 (Percy) cell inoculation $(88 \%)$ was obtained using nasal wash as the inoculum.

A single stock of SDAV was quantified concurrently in infant mice and trypsin-treated L2 (Percy) cells. The titer of stock SDAV-681 was $10^{6.4} \mathrm{LD}_{50}$ per $\mathrm{ml}$ in infant mice and $10^{4.5} \mathrm{TCID}_{50}$ per $\mathrm{ml}$ in trypsin-treated L2 (Percy) cells.

\section{Discussion}

Limited RCV growth was demonstrated in untreated L2 (Percy) and RBL-02 cells, but not in other cell lines tested, including LBC cells and an L2 subline obtained from another source. A recent observation of SDAV antigen in transitional epithelium of experimentally infected athymic rats [21] led us to assess rat bladder epithelial cell lines for growth of RCVs, and RBL-02 cells supported RCV growth on initial passage. Of the cell lines and treatments tested, L2 (Percy) cells treated with trypsin supported maximal growth of RCVs as evidenced by syncytium formation and viral antigen. RCV growth in L2 (Percy) cells was not enhanced by trypsin treatment of later passages when the enzyme was added at the time of virus inoculation. Adding trypsin at a different time in the RCV replicative cycle might enhance RCV growth in successive passages. As previously reported by Percy et al. [11], repeated passage of SDAV-681 in untreated L2 (Percy) cells increased viral growth. Repeated passage of other animal-adapted RCV strains in L2 (Percy) cells may accomplish adaptation and increased virus yield.

Trypsin, but not DEAE-D, enhanced RCV growth in L2 (Percy) cells. The mechanism by which trypsin increases RCV growth in these cells is not known. However, trypsin enhances mouse hepatitis virus (MHV) plaque formation $[15$, 19] and cleaves the $180 \mathrm{k} \mathrm{E} 2$ glycoprotein of MHV A59 into two $90 \mathrm{k}$ fragments [17]. Cleavage is associated with a two-fold increase in infectivity and with activation of the cell-fusing activities of virions in vivo $[16,17]$. Therefore, trypsin could enhance RCV infectivity by cleaving its E2 protein analogue.

Trypsin treatment of L2 (Percy) cells permitted primary isolation of SDAV from tissues of infected rats without repeated passage. The use of trypsin-treated L2 (Percy) cells to screen tissues for RCVs would significantly reduce animal use and expense. However, L2 (Percy) cells were about $2 \log _{10}$ less sensitive than infant mice based on comparative titration of SDAV-681. This may have been due to adaptation of stock SDAV-681 to infant mouse brain by virtue of multiple prior passages in mice. If trypsin-treated L2 (Percy) cells are inherently less sensitive than infant mice, tissues that are virus-negative by assay in these cells should be re-tested in mice to eliminate false negatives. Uninfected L2 (Percy) cells are morphologically heterogeneous and sensitive to tissue toxicity; therefore, antigen detection which is less subjective than interpretation of morphologic changes should be the definitive test used after cell culture inoculation. 
Using trypsin-treated L2 (Percy) cells, virus in lacrimal gland was more difficult to detect than virus in other tissues tested. A possible explanation for low isolation rates from lacrimal gland is the presence of a trypsin-inhibitor that is not present in other tissues. However, litters of mice inoculated with lacrimal gland homogenates tended to have lower mortality rates and deaths that occurred later than in groups inoculated with other tissues (data not shown). This suggests that lacrimal gland samples may simply have contained lower concentrations of virus.

RCV growth was increased in LBC and RBL-02 cells treated with DEAEdextran, a chemical that enhances virus binding and uptake by altering electrostatic interactions [1]. This result suggests that virus attachment and/or penetration are the limiting steps for RCV growth in these cell lines. DEAED also enhances infection of cells with MHV-3 [19], although the mechanism is unknown. Studies of binding and internalization with MHV-JHM have shown, however, that several rat cell lines share a common deficiency at the level of virus internalization [7]. DEAE-D may act by enhancing RCV binding to LBC and RBL-02 cells, thereby facilitating viral entry into cells that otherwise support RCV growth.

Little is known about the replication and biochemistry of RCVs largely due to their fastidious in vitro growth requirements. Our described refinements of in vitro growth conditions for RCVs should facilitate both in vitro and in vivo studies. Repeated passage of rat-adapted RCV isolates and RCV growth in L2 (Percy) and RBL-02 cells may increase virus yield and permit more sophisticated studies of antigenic relatedness among RCV isolates. Use of trypsin-treated L2 (Percy) cells should facilitate in vivo studies of RCV pathogenesis requiring $\mathrm{RCV}$ isolation.

\section{Acknowledgements}

The authors thank Dr. Dean Percy, Ontario Veterinary College, for L2 cells; Dr. Peter Tattersall, Yale University, for 3T3 cells and SV-40 transformation of HH cells; Dr. Laurence Sturman, New York State Department of Health, for $17 \mathrm{Cl} 1$ and L2 cells; Dr. Joseph Leighton, The Medical College of Pennsylvania, for NBT-II cells; Dr. Bendicht U. Pauli, New York College of Veterinary Medicine, for RBTCC-8 (F5), RBTCC-8 (F6) and RBTC1 cells; and Dr. James E. Klaunig, Medical College of Ohio, for AY-27 and RBL-02 cells. Supported by PHS Grant No. RR00393.

\section{References}

1. Bailey CA, Miller DK, Lenard J (1984) Effects of DEAE-Dextran on infection and hemolysis by VSV. Evidence that nonspecific electrostatic interactions mediate effective binding of VSV to cells. Virology 133: 111-118

2. Bhatt PN, Jacoby RO (1977) Experimental infection of adult axenic rats with Parker's rat coronavirus. Arch Virol 54: 345-352

3. Bhatt PN, Jacoby RO, Jonas AM (1977) Respiratory infection in mice with sialodacryoadenitis virus, a coronavirus of rats. Infect Immun 18: 823-827

4. Hirano N, Ono K, Sada Y, Inoue A, Murakami T (1985) Replication of rat coronavirus in a rat cell line, LBC. Brief report. Arch Virol 85: 301-304 
5. Holmes KV, Boyle JF, Frana MF (1986) Mouse hepatitis virus: molecular biology and implications for pathogenesis. In: Bhatt PN, Jacoby RO, Morse HC, New AL (eds) Viral and mycoplasmal infections of laboratory rodents: effects of biomedical research. Academic Press, San Francisco, pp 603-624

6. Flintoff WF, Van Dinter S (1989) Several rat cell lines share a common defects in their inability to internalize murine coronaviruses efficiently. J Gen Virol 70: 1713-1724

7. Jacoby RO (1986) Rat coronavirus. In: Bhatt PN, Jacoby RO, Morse HC, New AL (eds) Viral and mycoplasmal infections of laboratory rodents: effects on biomedical research. Academic Press, San Francisco, pp 625-640

8. Leighton J, Tchao R, Nichols J (1985) Radial gradient culture on the inner surface of collagen tubes: organoid growth of normal rat bladder and rat bladder cancer cell line NBT-II. In Vitro Cell Dev Biol 21: 713-715

9. Lenette EH, Schmidt NJ (eds) (1979) Cell culture techniques for diagnostic virology. American Public Health Association, Washington, DC, pp 65-140 (Diagnostic procedures for viral, rickettsial and chlamydial infections).

10. Pauli BU, Weinstein RS (1982) Correlations between cell surface protease activities and abnormalities of occludens junctions in rat bladder carcinoma in vitro. Cancer Res 42: 2289-2297

11. Percy D, Bond S, MacInnes J (1989) Replication of sialodacryoadenitis virus in mouse L-2 cells. Arch Virol 104: 323-334

12. Reed LJ, Muench H (1938) A simple method of estimating fifty percent endpoints. Am J Hyg 27: 493-497

13. Shulok JR, Klaunig JE, Selman SH, Schafer PJ, Goldblatt PJ (1986) Cellular effects of haematoporphyrin derivitive photodynamic therapy on normal and neoplastic rat bladder cells. Am J Pathol 122: 265-283

14. Smith AL (1983) An immunofluorescence test for detection of serum antibody to rodent coronaviruses. Lab Anim Sci 33: 157-160

15. Storz AJ, Rott R, Kaluza G (1981) Enhancement of plaque formation and cell fusion of an enteropathogenic coronavirus by trypsin treatment. Infect Immun 31: 1214-1222

16. Sturman LS, Holmes KV (1977) Characterization of a coronavirus. II Glycoproteins of the viral envelope: tryptic peptide analysis. Virology 77: 650-660

17. Sturman LS, Ricard CS, Holmes KV (1985) Proteolytic cleavage of the E2 glycoprotein of murine coronavirus: activation of cell-fusing activity of virions by trypsin and separation of two different $90 \mathrm{~K}$ cleavage fragments. J Virol 56: $904-911$

18. Sturman LS, Takemoto KK (1972) Enhanced growth of a murine coronavirus in transformed mouse cells. Infect Immun 6: 501-507

19. Takayama N, Kirn A (1976) An improved method for titration of mouse hepatitis virus type 3 in a mouse cell line. Arch Virol 52: 347-349

20. Tattersall $\mathbf{P}$, Bratton $\mathbf{J}$ (1983) Reciprocal productive and restrictive virus - cell interactions of immunosupressive and prototype strains of minute virus of mice. $J$ Virol 46: $944-955$

21. Weir EC, Jacoby RO, Paturzo FX, Johnson EA, Ardito RB (1990) Persistence of sialodacryoadenitis virus in athymic rats. Lab Anim Sci 40: 138-143

Authors' address: Dr. Diane J. Gaertner, Section of Comparative Medicine, Yale University School of Medicine, 333 Cedar Street, P.O. Box 3333, New Haven, CT 06510, U.S.A.

Received October 2, 1990 